\title{
Characteristics Associated With Bone Mineral Density Screening in Adults With Intellectual Disabilities
}

\author{
Deborab Dreyfus, MD, MSc, Emily Lauer, MPH, and Joanne Wilkinson, MD, MSc
}

Background: Certain health characteristics place adults with intellectual disability at increased risk for osteoporosis. However, little data exist to describe how comorbid disease or medications affect screening patterns for these patients.

Methods: We evaluated the relationship between bone density screening and the presence of risk factors using a secondary cross-sectional analysis of 5520 adults aged 19 years and older with the diagnosis of intellectual disability.

Results: Of the sample, $22.9 \%$ received one or more bone density screenings (34.4\% women, $13.3 \%$ men). Low screening rates in men prohibited the construction of a valid sex-specific multivariate model of the association between bone density screening and risk factors for osteoporosis. In women, when controlling for age the following factors were significantly associated with ever having bone density screening: use of antiepileptic medication (odds ratio [OR], 1.5) and vitamin D (OR, 3.4); recent receipt of a flu vaccine $(\mathrm{OR}, 1.4)$; and living in a 24-hour supported residential setting $(\mathrm{OR}, 1.3)$. A diagnosis of Down syndrome (OR, 0.72) was associated with decreased likelihood of screening.

Conclusions: Many known risk factors for osteoporosis affected the likelihood of an adult with intellectual disability receiving screening, yet overall screening rates for adults with intellectual disabilities were lower than screening rates in the general population. Results suggest a need for increased provider awareness about bone density screenings in high-risk adults with intellectual disability, especially men, as well as men and women with Down syndrome. (J Am Board Fam Med 2014;27:104-114.)

Keywords: Delivery of Health Care, Developmental Disabilities, Down Syndrome, Osteoporosis

Osteoporosis is the diagnostic term for low bone mineral density, a condition that leads to increased morbidity and mortality in the form of increased hip and vertebral fractures. The risk of osteoporosis is higher among adults with intellectual disability than it is among the general population, with some

This article was externally peer reviewed.

Submitted 8 April 2013; revised 15 July 2013; accepted 22 July 2013.

From the Department of Family Medicine, Boston University, Boston, MA (DD, JW); and the Center for Developmental Disabilities Evaluation and Research, Eunice Kennedy Shriver Center, University of Massachusetts Medical School, Boston, MA (EL).

Funding: This study was funded by a Foundation Grant from the American Academy of Family Physicians (grant no. G1006RS).

Conflict of interest: none declared.

Corresponding author: Deborah Dreyfus, MD, MSc, Department of Family Medicine, Boston University, One Boston Medical Center Place, Dowling 5 South, Boston, MA 02118 (E-mail: deborah.dreyfus@bmc.org). studies estimating fractures occurring anywhere from 1.7 to 3.5 times more often among people with developmental disabilities. ${ }^{1-6}$ Intellectual disability is defined as a chronic disability occurring before the age of 18 years and causing limitations in the areas of intellectual functioning and adaptive behaviors such as receptive and expressive language, interpersonal skills, and practical skills. ${ }^{7}$ Adults with an intellectual disability may experience low bone mineral density because of decreased ambulation, lack of exercise, lack of nutrition (difficulty swallowing is a risk factor for poor nutrition, which in turn is a risk factor for low bone mineral density), decreased exposure to sunlight (leading to vitamin D deficiency), medications (eg, antiseizure medications are more often used by adults with intellectual disability), race, Down syndrome, and hypogonadism (women with intellectual disability have amenorrhea more more than woman in the 
general population). ${ }^{4-6,8-10,15,17}$ It is interesting that previous small studies have shown that men with intellectual disability have a high risk of osteoporosis. ${ }^{13,14}$ While studies of this population are indeed small (in general, 100 to 500 individuals participating), this indicates a heightened need for concern about osteoporosis in men. ${ }^{15}$ In addition, osteoporosis and osteopenia often occur at younger ages for people with intellectual disability than the general population. Indeed, there have been some studies indicating a first fracture occurring in the early 40s among people with intellectual disability. ${ }^{2,13,15}$

For the general population, the US Preventive Services Task Force recommends starting screening at $\geq 65$ years for women and younger for women with risk factors; at this time there is insufficient evidence to recommend screening for men. ${ }^{16}$ However, recommendations vary regarding bone density screening for people with intellectual disability. Screening guidelines for adults with intellectual disability have been developed by an expert panel convened by the Massachusetts Department of Developmental Services (DDS), a state government organization that provides programs and support for adults with intellectual disability. This guideline recommends screening for people with intellectual disability beginning at 19 years old. ${ }^{12,17,18}$ In addition, findings of a 2007 meta-analysis of screening guidelines for adults with intellectual disability suggest that screening should start at age 45 years, based on expert opinion. ${ }^{19}$ At this time there are no evidence-based guidelines for screening in adults with intellectual disability. Little is known regarding actual practices of bone density screening in the community for this population, in part because no large studies describing factors associated with bone density screening for people with intellectual disability have been conducted.

We undertook a study to examine how characteristics known to influence bone density for both men and women with and without intellectual disability $^{4-6,8-11,15-17,20-23,24-29}$ affect bone density screening in people with intellectual disability.

\section{Methods \\ Subjects}

In this study we chose to analyze data from the Massachusetts DDS because the agency maintains a comprehensive, organized health database that includes data on many types of screenings (this database is discussed below). In addition, the Massachusetts DDS has a process in place to determine eligibility for services that excludes people without intellectual disability. Furthermore, Massachusetts has legislated universal health care coverage that pays for preventive services, eliminating lack of insurance as a confounding factor to screening, as evidenced by the uninsured rate in Massachusetts being approximately $1.9 \%$ in $2010,{ }^{30}$ compared with $16.3 \%$ of the overall US population. ${ }^{31}$

\section{Database}

In 2006, the Massachusetts DDS created an electronic administrative health database to track client health and facilitate communication between providers in an effort to optimize health care delivery for people who receive services from the DDS. It is important to distinguish the DDS health database from electronic medical records maintained by medical professionals and used to track medical care. This data system contains information about approximately 12,500 adults in the state of Massachusetts and includes information related to functional status and special care conditions related to medical care. Those who received services are more likely to appear in the database if they actively receive certain types of services from the DDS, including residential services, placement services, and individualized home support, where the provider is responsible for coordinating the health care of the individual. The DDS requires these service providers (such as group home management agencies) to update this database at least annually. The DDS also recommends that the database be updated any time there are significant changes in the individual's information. The database was not created for research purposes; however, it has been recently noted that the health record is a rich source of information for research purposes.

To protect the privacy of the people in this database, a DDS consultant who regularly accesses this information de-identified the subjects before analysis. We received an exemption letter from the Boston University Medical Center Institutional Review Board and approval from the DDS Research Review Committee for the study.

To prove validity and reproducibility of the information in this database, we performed a preliminary analysis that showed that the DDS database is 
Table 1. Bivariate Analysis: Men

\begin{tabular}{|c|c|c|c|c|}
\hline Variable & People (n) & $\begin{array}{c}\text { People Who Were } \\
\text { Screened }(\%)\end{array}$ & Crude OR & $95 \% \mathrm{CI}$ \\
\hline \multicolumn{5}{|l|}{ Individual characteristics } \\
\hline \multicolumn{5}{|l|}{ Age (years) } \\
\hline $19-24$ & 293 & 5.1 & 0.13 & $0.06-0.03$ \\
\hline $25-34$ & 544 & 9.2 & 0.24 & $0.13-0.44$ \\
\hline $35-44$ & 775 & 10.8 & 0.29 & $0.17-0.52$ \\
\hline $45-54$ & 757 & 14.1 & 0.40 & $0.23-0.69$ \\
\hline $55-64$ & 407 & 20.6 & 0.62 & $0.35-1.1$ \\
\hline $65-74$ & 162 & 25.3 & 0.81 & $0.43-1.5$ \\
\hline$\geq 75$ & 68 & 29.4 & \multicolumn{2}{|c|}{ Reference } \\
\hline \multicolumn{5}{|l|}{ Antiepileptic medications } \\
\hline Yes & 919 & 18.9 & 1.9 & $1.5-2.4$ \\
\hline No & 2087 & 10.9 & \multicolumn{2}{|c|}{ Reference } \\
\hline \multicolumn{5}{|l|}{ Proton pump inhibitor } \\
\hline Yes & 521 & 20.2 & 1.9 & $1.5-2.4$ \\
\hline No & 2485 & 11.9 & \multicolumn{2}{|c|}{ Reference } \\
\hline \multicolumn{5}{|l|}{ Vitamin D } \\
\hline Yes & 202 & 43.1 & 6.0 & $4.4-8.1$ \\
\hline No & 2804 & 11.2 & \multicolumn{2}{|c|}{ Reference } \\
\hline \multicolumn{5}{|l|}{ Special positioning } \\
\hline Yes & 119 & 27.7 & 2.6 & $1.7-3.9$ \\
\hline No & 2679 & 13.0 & \multicolumn{2}{|c|}{ Reference } \\
\hline \multicolumn{5}{|l|}{ Ambulation } \\
\hline Any assistance needed & 776 & 24.7 & 3.2 & $2.6-3.9$ \\
\hline Independent & 2194 & 9.4 & \multicolumn{2}{|c|}{ Reference } \\
\hline \multicolumn{5}{|l|}{ History of fracture } \\
\hline Yes & 346 & 28.9 & 3.2 & $2.5-4.1$ \\
\hline No & 2660 & 11.3 & \multicolumn{2}{|c|}{ Reference } \\
\hline \multicolumn{5}{|l|}{ Cooperates with exams } \\
\hline Uncooperative & 1318 & 15.2 & 1.3 & $1.1-1.6$ \\
\hline Cooperative & 1688 & 11.9 & \multicolumn{2}{|c|}{ Reference } \\
\hline \multicolumn{5}{|l|}{ Thyroid abnormalities } \\
\hline Yes & 365 & 17.0 & 1.4 & $1.0-1.9$ \\
\hline No & 2641 & 12.8 & \multicolumn{2}{|c|}{ Reference } \\
\hline \multicolumn{5}{|l|}{ Down syndrome } \\
\hline Yes & 368 & 8.7 & 0.58 & $0.40-0.86$ \\
\hline No & 2638 & 14.0 & \multicolumn{2}{|c|}{ Reference } \\
\hline \multicolumn{5}{|l|}{ Diet texture } \\
\hline Unusual & 648 & 22.7 & 2.4 & $1.9-3.0$ \\
\hline Normal & 2324 & 10.8 & \multicolumn{2}{|c|}{ Reference } \\
\hline Interpersonal characteristic & & & & \\
\hline Guardian & & & & \\
\hline Yes & 2026 & 14.7 & 1.5 & $1.2-1.9$ \\
\hline No & 980 & 10.5 & $\operatorname{Re}$ & \\
\hline Received a flu shot durin & & & & \\
\hline Yes & 1850 & 16.7 & 2.3 & $1.8-2.9$ \\
\hline No & 1156 & 8.0 & & \\
\hline
\end{tabular}

Continued 


\begin{tabular}{|c|c|c|c|c|}
\hline Variable & People (n) & $\begin{array}{l}\text { People Who Were } \\
\text { Screened }(\%)\end{array}$ & Crude OR & $95 \% \mathrm{CI}$ \\
\hline \multicolumn{5}{|c|}{ Organizational characteristics } \\
\hline \multicolumn{5}{|l|}{ Residential setting } \\
\hline 24-hour support & 1952 & 15.7 & 1.9 & $1.5-2.2$ \\
\hline$<24$-hour support & 1054 & 8.9 & \multicolumn{2}{|c|}{ Reference } \\
\hline \multicolumn{5}{|c|}{ Nursing-supported care coordination } \\
\hline Yes & 1175 & 14.6 & 1.2 & $0.96-1.5$ \\
\hline No & 1710 & 12.5 & \multicolumn{2}{|c|}{ Reference } \\
\hline
\end{tabular}

CI, confidence interval; OR, odds ratio.

most generalizable to women with intellectual disability who are living in residential settings with 24-hour support ( $92 \%$ of consumers in this group were represented). Consumers living independently had much lower representation in the database. $^{32}$

\section{Inclusion/Exclusion Criteria}

De-identified health records were analyzed between July 1, 2007, and June 30, 2009, for the occurrence of "ever having bone densitometry performed." The database captured the date of the last screening, even if it did not occur between 2007 and 2009. We included all men and women who were $\geq 19$ years old at the start of the study period. People were excluded if they already had a diagnosis of osteoporosis or were receiving treatment for osteoporosis. Consumers who did not have an entry for the last date of bone density screening (the entry was missing a value) were removed from the analysis.

\section{Definitions of Independent and Dependent Variables \\ Dependent Variable}

We defined "ever having bone densitometry performed" as a yes/no dependent variable. We chose "ever having bone densitometry performed" as opposed to "bone density screening during the 2-year period studied" because screening recommendations vary, and a narrow period likely would have missed those who were screened at an interval suggested by their treating practitioner.

\section{Independent Variables and the Conceptual Framework}

The ecological framework was used to organize variables and interpret findings. This conceptual framework examines a health behavior as a series of "layers" of factors that influence behavior, which are divided into 5 groups: individual, interpersonal, organizational, community, and public policy. ${ }^{33,34}$ Because intellectual limitations can affect multiple areas of function, and because health care coordination often involves the support of other people, this model of health behavior is highly relevant to the screening of people with intellectual disabilities. The variables in this study were divided into these categories under this framework for organization.

Exposures evaluated included individual characteristics such as fracture history, ambulatory status/ wheelchair use, medication use, double staffing required during exams, genetic syndromes, family history of fracture, special positioning required during exams, and reportedly being uncooperative or needing sedation during exams. Information on race/ethnicity, which often is predictive of receipt of screening in the general population, was not consistently available in the DDS health database. Exposures also included interpersonal characteristics such as guardian status and organizational characteristics such as health care coordination performed by nurses. To control for exposure bias due to age in our dependent variable of "ever screened," analyses controlled for age. There was insufficient information available to control for community or public policy factors; in addition, as discussed earlier, insurance coverage was consistent across adults in this study. A complete list of all variables by domain is presented in Tables 1 and 2 .

\section{Epidemiologic and Statistical Analysis}

Odds ratios (ORs) were calculated to estimate the strength of association between each independent 
Table 2. Bivariate Analysis: Women

\begin{tabular}{|c|c|c|c|c|}
\hline Variable & People (n) & $\begin{array}{c}\text { People Who Were } \\
\text { Screened (\%) }\end{array}$ & Crude OR & $95 \% \mathrm{CI}$ \\
\hline \multicolumn{5}{|l|}{ Individual characteristics } \\
\hline \multicolumn{5}{|l|}{ Age (years) } \\
\hline $19-24$ & 228 & 11.0 & 0.048 & $0.022-0.11$ \\
\hline $25-34$ & 513 & 11.9 & 0.054 & $0.026-0.11$ \\
\hline $35-44$ & 624 & 22.3 & 0.11 & $0.056-0.22$ \\
\hline $45-54$ & 657 & 44.9 & 0.32 & $0.16-0.63$ \\
\hline $55-64$ & 337 & 67.3 & 0.81 & $0.40-1.6$ \\
\hline $65-74$ & 110 & 79.8 & 1.5 & $0.69-3.5$ \\
\hline$\geq 75$ & 43 & 72.1 & & nce \\
\hline \multicolumn{5}{|l|}{ Antiepileptic medications } \\
\hline Yes & 696 & 41.8 & 1.6 & $1.3-1.9$ \\
\hline No & 1811 & 31.5 & \multicolumn{2}{|c|}{ Reference } \\
\hline \multicolumn{5}{|l|}{ Proton Pump Inhibitor } \\
\hline Yes & 388 & 44.9 & 1.7 & $1.4-2.1$ \\
\hline No & 2119 & 32.5 & \multicolumn{2}{|c|}{ Reference } \\
\hline \multicolumn{5}{|l|}{ Vitamin D } \\
\hline Yes & 406 & 63.3 & 4.3 & $3.4-5.3$ \\
\hline No & 2101 & 28.8 & \multicolumn{2}{|c|}{ Reference } \\
\hline \multicolumn{5}{|l|}{ Depo-Provera use } \\
\hline Yes & 132 & 40.2 & 1.3 & $0.91-1.9$ \\
\hline No & 2375 & 34.1 & \multicolumn{2}{|c|}{ Reference } \\
\hline \multicolumn{5}{|l|}{ Menstruation } \\
\hline Yes & 1527 & 19.9 & 0.18 & $0.15-0.22$ \\
\hline No & 810 & 57.7 & \multicolumn{2}{|c|}{ Reference } \\
\hline \multicolumn{5}{|l|}{ Special positioning } \\
\hline Yes & 110 & 40.0 & 1.3 & $0.86-1.9$ \\
\hline No & 2211 & 34.3 & \multicolumn{2}{|c|}{ Reference } \\
\hline \multicolumn{5}{|l|}{ Ambulation } \\
\hline Any assistance needed & 801 & 46.3 & 2.1 & $1.8-2.5$ \\
\hline Independent & 1665 & 28.8 & \multicolumn{2}{|c|}{ Reference } \\
\hline \multicolumn{5}{|l|}{ History of fracture } \\
\hline Yes & 313 & 47.9 & 1.9 & $1.5-2.4$ \\
\hline No & 2194 & 32.5 & \multicolumn{2}{|c|}{ Reference } \\
\hline \multicolumn{5}{|l|}{ Cooperates with exams } \\
\hline Uncooperative & 1055 & 35.0 & 1.0 & $0.89-1.2$ \\
\hline Cooperative & 1452 & 34.0 & \multicolumn{2}{|c|}{ Reference } \\
\hline \multicolumn{5}{|l|}{ Thyroid abnormalities } \\
\hline Yes & 539 & 43.4 & 1.6 & $1.3-2.0$ \\
\hline No & 1968 & 31.9 & \multicolumn{2}{|c|}{ Reference } \\
\hline Down syndrome & & & & \\
\hline Yes & 295 & 28.1 & 0.72 & $0.55-0.94$ \\
\hline No & 2212 & 35.2 & & nce \\
\hline Diet texture & & & & \\
\hline Unusual & 546 & 46.7 & 2.0 & $1.6-2.4$ \\
\hline Normal & 1930 & 30.9 & & nce \\
\hline Interpersonal characteristics & & & & \\
\hline Guardian & & & & \\
\hline Yes & 1563 & 35.7 & 1.2 & $0.98-1.4$ \\
\hline No & 944 & 32.2 & & nce \\
\hline
\end{tabular}

Continued 
Table 2. Continued

\begin{tabular}{|c|c|c|c|c|}
\hline Variable & People (n) & $\begin{array}{l}\text { People Who Were } \\
\text { Screened (\%) }\end{array}$ & Crude OR & $95 \% \mathrm{CI}$ \\
\hline \multicolumn{5}{|c|}{ Received a flu shot during the time period studied } \\
\hline Yes & 1621 & 40.4 & 2.2 & $1.8-2.7$ \\
\hline No & 886 & 23.4 & \multicolumn{2}{|c|}{ Reference } \\
\hline \multicolumn{5}{|c|}{ Organizational characteristics } \\
\hline \multicolumn{5}{|l|}{ Residential setting } \\
\hline 24-hour support & 1570 & 39.2 & 1.8 & $1.5-2.2$ \\
\hline$<24$-hr support & 937 & 26.3 & \multicolumn{2}{|c|}{ Reference } \\
\hline \multicolumn{5}{|c|}{ Nursing-supported care coordination } \\
\hline Yes & 930 & 36.3 & 1.2 & $0.98-1.4$ \\
\hline No & 1497 & 32.9 & \multicolumn{2}{|c|}{ Reference } \\
\hline
\end{tabular}

CI, confidence interval; OR, odds ratio.

variable and receipt of screening using $\chi^{2}$ analysis. The statistical stability of the bivariate odds ratios was assessed using $95 \%$ confidence intervals (CIs).

A Pearson correlation matrix was used to assess for collinearity between independent variables under consideration for inclusion in the multivariate model. If variables were correlated $(r>.4$; most variables were dichotomous), only one of the variables was included. Since screening recommendations for men in the general population are different from the recommendations for women, separate sexspecific models were created to empirically identify factors associated with screening for each sex. Some covariates, such as birth control use, only pertained to one sex and were only included in the appropriate sex-specific model. A multivariate logistic regression then was constructed using stepwise reduction and controlling for age to adjust for different exposure times. $P>.05$ was the cutoff value for elimination. Log likelihood ratio tests were used to further assess model fit. Variables that did not significantly contribute to the model fit were removed. Discrimination, calibration, sensitivity, specificity, the pseudo $r^{2}$, and the receiver operating characteristics curve were calculated for each model.

\section{Results}

After removing subjects who met the exclusion criteria, had missing data, or both, 5520 people remained (2512 women and 3008 men) (see Figure 1). The average age of included female subjects was 43.4 years (range, 19.1-89.0 years). The average age of male subjects was 44.1 (range, 19.4-89.0 years). Of the women included, $34.4 \%(\mathrm{n}=862)$ had ever re- ceived a bone density screening; $13.3 \%$ of men ( $\mathrm{n}=$ 401) had ever received bone density screening.

\section{Bivariate Analysis}

For women, the following variables were associated with increased likelihood of screening: use of vita$\min \mathrm{D}(\mathrm{OR}, 4.3$; 95\% CI, 3.4-5.3), recent receipt of a flu vaccine (OR, 2.2; 95\% CI, 1.8-2.7), living in a residence providing 24-hour support (OR, 1.8; $95 \% \mathrm{CI}, 1.5-2.2)$, and the use of antiepileptic medication (OR, 1.6; 95\% CI, 1.3-1.9). Having a diagnosis of Down syndrome (OR, 0.72; 95\% CI, 0.55 0.94 ) and lack of menstruation (OR, $0.18 ; 95 \%$ CI, $0.15-0.22)$ were associated with a decreased likelihood of screening. Results for sex-neutral variables were similar for men (see Table 1).

\section{Multivariate Logistic Regression}

The fit of each stratified model was assessed. The female model had a c statistic of 0.81 . The sensitivity and the specificity were $55.0 \%$ and $87.0 \%$, respectively. The male model had a $\mathrm{c}$ statistic of 0.76 . The sensitivity and specificity were $12.3 \%$ and $98.6 \%$, respectively. On the basis of the low screening rate among men and the resulting low sensitivity of the male model, there was insufficient variation in the outcome to assess the likelihood of screening with this dataset. Thus, we focused on the female model for all further analyses.

\section{The Female Model}

Selected factors associated with an increased odds of screening included the use of antiepileptic medications (adjusted OR, 1.5; 95\% CI, 1.21.9) and vitamin $\mathrm{D}$ (adjusted OR, 3.4; 95\% CI, 
Figure 1. Patients participating in the study.

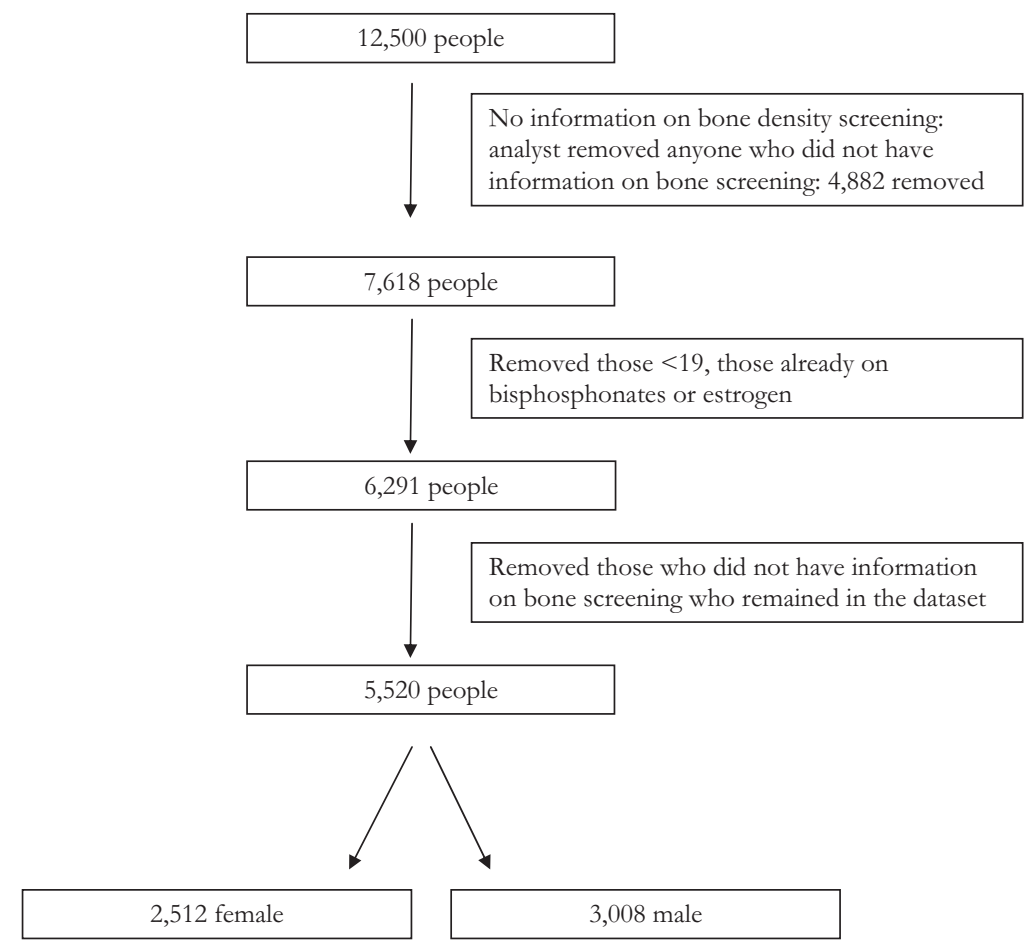

2.6-4.4), recent receipt of a flu vaccine (adjusted OR, 1.4; 95\% CI, 1.1-1.8), and living in a $24-$ hour residential setting (adjusted OR, 1.3; 95\% CI, 1.1-1.7). Down syndrome (adjusted OR, 0.72 ; $95 \%$ CI, $0.52-0.98$ ) was a factor associated with a decreased likelihood of screening. See Table 3 for the complete list of factors associated with screening.

\section{Discussion}

While data for bone density screening rates in the general Massachusetts population are unavailable, screening rates for women with intellectual disability in this study show evidence of disparity compared with the total number of postmenopausal women who had ever received a bone density screening in the US. In particular, women $\geq 65$ years old in this dataset had a rate of screening of $22.7 \%$, compared with a rate of $71 \%$ of women $>65$ ever having been screened in the US in 2008 . $^{35}$ The low rate of screening for women with intellectual disability suggests that not enough providers are aware of the increased risk of osteoporosis in individuals with intellectual disabilities. Of note, the rates of screening are not in alignment with the Massachusetts DDS published guidelines, which recommend screening be initiated at 19 years of age.

Factors such as the use of anticonvulsive medication, recently receiving a flu vaccine, and use of 24-hour residential support were all significantly positively associated with the receipt of screening when controlled for age and other factors. The association of anticonvulsive medication with screening was an expected finding based on supportive evidence that anticonvulsive medications decrease vitamin D metabolism and therefore lead to decreased bone synthesis. ${ }^{24}$ This association may suggest that physicians are aware of the increased risk inherent in the use of anticonvulsants and are screening as recommended. In addition, receipt of a recent flu vaccination served as a proxy measure to identify those who receive other preventive health care services. We hypothesized that individuals who receive one form of preventive care would be more likely to receive another form of screening. Other studies have shown that adults with intellectual disability are more likely to receive flu vaccines than other forms of screening, such as cervical cancer screening, ${ }^{36}$ likely because of the ease of administration. This study compliments the findings of those other studies because those receiving 
Table 3. Logistic Regression: Female Model

\begin{tabular}{|c|c|c|c|}
\hline Variable & Crude OR & Adjusted OR & $95 \% \mathrm{CI}$ \\
\hline \multicolumn{4}{|l|}{ Individual characteristics } \\
\hline \multicolumn{4}{|l|}{ Age (years) } \\
\hline $19-24$ & 0.048 & 0.068 & $0.03-0.16$ \\
\hline $25-34$ & 0.052 & 0.062 & $0.029-0.13$ \\
\hline $35-44$ & 0.11 & 0.12 & $0.06-0.25$ \\
\hline $45-54$ & 0.32 & 0.36 & $0.18-0.75$ \\
\hline $55-64$ & 0.80 & 0.93 & $0.45-1.9$ \\
\hline $65-74$ & 1.5 & 1.6 & $0.69-3.7$ \\
\hline$\geq 75$ (Reference) & 1.0 & 1.0 & Reference \\
\hline Antiepileptic medication & 1.6 & 1.5 & $1.2-1.9$ \\
\hline Proton pump inhibitor & 1.7 & 1.3 & $1.0-1.7$ \\
\hline Vitamin D & 4.3 & 3.4 & $2.6-4.4$ \\
\hline Depo-Provera use & 1.3 & 1.8 & $1.2-2.7$ \\
\hline Down syndrome & 0.72 & 0.72 & $0.52-0.98$ \\
\hline Needs assistance with ambulation & 2.1 & 1.3 & $1.0-1.6$ \\
\hline History of fracture & 1.9 & 1.3 & $1.0-1.8$ \\
\hline Cooperative with exams & 1.0 & 0.70 & $0.56-0.87$ \\
\hline \multicolumn{4}{|l|}{ Interpersonal characteristic } \\
\hline Received a flu shot during the time period studied & 2.2 & 1.4 & $1.1-1.8$ \\
\hline \multicolumn{4}{|l|}{ Organizational characteristic } \\
\hline 24-hour supported residential setting & 1.8 & 1.3 & $1.1-1.7$ \\
\hline
\end{tabular}

CI, confidence interval; OR, odds ratio.

flu vaccines were more likely to receive bone density screening.

Finally, women living in a residential setting with 24-hour support may have been associated with increased screening because of the additional support with health care coordination in these settings, compared with women who live more independently, with family, or both. The additional specialized supports and organizational structures in 24-hour residential settings may mitigate some personal, interpersonal, organizational, or policylevel barriers to screening. It is also possible that formal and informal advocacy exists in 24-hour residential settings because of the presence of clinical and trained nonclinical staff members. This effect was observed in another study examining mammography screening in women with intellectual disability that used the same DDS database. This study found that that those living in a residential setting with 24-hour support were $40 \%$ more likely to receive mammograms than women who lived in other settings, ${ }^{37}$ suggesting that residential setting and support staff may play an important role in advocating for screening.

The variable most significantly positively associated with screening was receipt of vitamin D supplements. We hypothesize that this association might be due to increased access to preventive care, in that a prescription for vitamin $\mathrm{D}$ might be a proxy measure for receipt of primary care, and in residential services in Massachusetts a prescription is required to administer any supplements. However, vitamin $\mathrm{D}$ supplementation might also have been prescribed because the individual presented with known risk factors for osteoporosis. It is also possible that noting a prescription for vitamin $\mathrm{D}$ in the patient's medical record may have cued some providers to order bone density screening because prescription of vitamin D may signal risk factors for osteoporosis. Thus it is difficult to assess the temporality of vitamin $\mathrm{D}$, and we cannot conclude whether it was prescribed before or after screening or the causality of its relationship to bone density screening.

Surprising findings include the negative correlation between Down syndrome and bone density screening. This is an important observation because those with Down syndrome have an increased risk of developing osteoporosis. ${ }^{5,9}$ While studies specifically oriented toward fracture rate in people with Down syndrome are limited, the studies performed indicate low bone mineral density in those 
with Down syndrome. Research shows that individuals with Down syndrome are at higher risk of developing Alzheimer's disease as they age ${ }^{38}$; the dementia increases risk of fall, which identifies a further risk for fracture in an individual who already has lower bone mineral density. It is unclear why an inverse relationship between Down syndrome and screening exists in our study. Further research to clarify this relationship is needed.

In the unadjusted analyses, it was observed that amenorrhea was correlated with increased screening. While the variable was dropped because of concerns about collinearity, this is an important finding in that those with early ovarian failure are at high risk for osteoporosis. It is important that women with early menopause receive earlier bone density screening. Thus the strong correlation between amenorrhea and increased bone density screening is reassuring, in that providers seem to be screening those with amenorrhea more often than those with regular menses.

Low screening rates in men precluded an ability to provide multivariate analysis through a male regression model; however, it is important to note that the low occurrence of screening among men is an important finding alone because men with intellectual disability have more risk factors for developing osteoporosis compared with men in the general population, including anticonvulsive medication use, thyroid disease, and decreased ambulation. The American College of Physicians currently recommends all men (not only men with intellectual disability) receive screening if they have risk factors that predispose them to osteoporosis, including age $>70$ years, certain medication use (eg, corticosteroids), and decreased physical activity. ${ }^{39}$ It is known that men with intellectual disability are at higher risk for osteoporosis, and therefore the need for improved rates of screening in men is underscored by the screening rates observed in this study.

\section{Limitations}

There were several limitations to these analyses. First, because this is a cross-sectional study, we were unable to assess whether the exposures studied occurred before or after the screening. In addition, a significant number of potential subjects were excluded from analysis because of a lack of information regarding whether they had received bone density screenings. This may have occurred because of a lack of communication about the screening between the health care provider and the service agency, incomplete records for care that occurred before DDS involvement, or incomplete records from people who do not receive residential services and see their health care provider independently or with family. To identify differences between those individuals who were included in the study versus those who were not, we examined the distribution of descriptive statistics for the group with missing information using the same inclusion and exclusion criteria as those used in the study. Similar distributions were noted for all variables described in this study except vitamin D, menstruation, cooperation during exams, and recent flu vaccination. Those with information about their bone density screening status were more likely to be menstruating (65\% vs $18 \%$ ) and less cooperative during exams ( $42 \%$ vs $28 \%$ ). In addition, those included in the study were more likely to receive vitamin $\mathrm{D}$ supplementation (16\% vs $8 \%$ ) and have a report of a recent flu vaccination in their record (65\% vs 50\%); however, the availability of this medication and screening may be affected by the same issues affecting screening status (ie, incomplete records). In summary, in this study the variables describing the group without a screening status do not seem to differ substantially from the variables of those who did have a screening status reported.

Third, the database was not initially created for research. Therefore, some variables relevant to a study of this nature are missing (eg, there is no information on race/ethnicity). While generalizability may have some limitations due to Massachusetts' fairly unique health care policies, including universal health insurance, these findings demonstrate that even when insurance barriers are removed, significant additional barriers to bone density screening exist and affect the screening rate. Therefore, these findings may suggest modifiable determinants of screening even in states without universal coverage.

Because of the low number of men who were screened $(13 \%)$, the male model was not powered to identify characteristics associated with screening, as described earlier. Finally, by evaluating screening across the lifespan, we were not able to assess the frequency of screening. Because of the limited information on screening in this population, a lifespan screening perspective was chosen to provide a 
broad view of screening. Future studies examining screening patterns over more narrow timeframes may be useful to examine screening patterns at different points in the lifespan.

\section{Future Implications}

Many adults with intellectual disabilities are at an increased risk of osteoporosis. This study estimates the prevalence of bone density screening rates in a large population of recipients who receive intellectual disability-specific services. In addition, it identifies several individual, interpersonal, and organizational characteristics that may represent barriers to screening. Understanding these associations may help identify subpopulations in need of improvements in targeted screening rates. For example, based on this study, improvements to the bone density screening rates for adults with Down syndrome are needed. Because adults with Down syndrome have known risks for osteoporosis, further research is needed to identify why screening does not seem to occur as often for these individuals. Further research also is needed regarding reasons why screening rates were not higher for people with certain known risk factors for osteoporosis, including taking antiepileptic medications and limited mobility. In addition, continued research regarding the educational needs of physicians surrounding osteoporosis and bone density screening for adults with intellectual disabilities may be warranted. Finally, the association between vitamin D and increased screening rates warrants future investigation in a study other than a cross-sectional analysis to better characterize the relationship.

The authors thank Carl Tyler, MD, for assistance with content; Nechama Greenwood, CPM, for editorial assistance; and the Department of Developmental Services for their guidance.

\section{References}

1. Glick NR, Fisher MH, Heisey DM, Leverson GE, Mann DC. Epidemiology of fractures in people with severe and profound developmental disabilities. Osteoporosis Int 2005;16:389-96.

2. Schrager S, Kloss C, Ju AW. Prevalence of fractures in women with intellectual disabilities: a chart review. J Intellect Disabil Res 2007;51:253-9.

3. Jaffe MS, Timell AM, Elolia R, Thatcher SS. Risk factors for low bone mineral density in individuals residing in a facility for the people with intellectual disability. J Intellect Disabil Res 2005;49:457-62.
4. Tyler CV, Snyder CW, Zyzanski S. Screening for osteoporosis in community-dwelling adults with mental retardation. Ment Retard 2000;38:316-21.

5. Schrager S. Osteoporosis in women with disabilities. J Womens Health 2004;13:431-7.

6. Schrager S. Epidemiology of osteoporosis in women with cognitive impairment. Ment Retard 2006;44: 203-11.

7. Definition of intellectual disability 2008. Washington, DC: American Association on Intellectual and Developmental Disabilities. Available from: http://aaidd.org/ docs/default-source/sis-docs/aaiddfaqonid_template.pdf? svrsn=2. Accessed November 22, 2013.

8. Wagemans AM, Fiolet JF, Van DerLinden ES, Manheere PP. Osteoporosis and intellectual disability: is there any relation? J Intellect Disabil Res 1998;42:370-4.

9. Angelopoulou N, Souftas V, Sakadamis A, Mandroukas K. Bone mineral density in adults with Down's syndrome. Eur Radiol 1999;9:648-51.

10. Peterson J, Janz K, Lowe J. Physical activity among adults with intellectual disabilities living in community settings. Prev Med 2008;47:101-106.

11. Center JR, McElduff A, and Beange H. Osteoporosis in Groups with Intellectual Disability. J Intellect Develop Disabil 1994;19:251-258.

12. Agency for Healthcare Research and Quality. Massachusetts Department of Developmental Services adult screening recommendations 2012. Available from: http://www.guideline.gov/content.aspx?id=37906. Accessed November 9, 2013.

13. Zylstra RG, Porter LL, Shapiro JL, Prater CD. Prevalence of osteoporosis in community-dwelling individuals with intellectual and/or developmental disabilities. J Am Med Dir Assoc 2008;9:109-13.

14. Leslie WD, Roe EB, Dittberner K. Bone density and fragility fractures in patients with developmental disabilities. Osteoporosis Int 2009;20:379-83.

15. Jasien J, Daimon CM, Maudsley S, Shapiro BK, Martin B. Aging and bone health in individuals with developmental disabilities. Int J Endocrinol 2012; 2012: Study ID 469235.

16. Screening for osteoporosis. January 2011. Rockville, MD: U.S. Preventive Services Task Force. Available from: http://www.uspreventiveservicestaskforce.org/ uspstf/uspsoste.htm. Accessed November 9, 2013.

17. Massachusetts Department of Developmental Services. Massachusetts Department of Mental Retardation health screening recommendations. Boston (MA): Massachusetts Department of Developmental Services; 2007.

18. Sullivan WF, Hang J, Cameron D, et al. Consensus guidelines for primary health care of adults with developmental disabilities. Can Fam Physician 2006; 52:1410-8.

19. Wilkinson J, Culpepper L, Cerreto M. Screening tests for adults with intellectual disabilities. J Am Board Fam Med 2007;20:399-407. 
20. Johansson H, Kanis JA, Oden A, Johnell O, McCloskey E. BMD, clinical risk factors and their combination for hip fracture prevention. Osteoporosis Int 2009; 20:1675-82.

21. Cromer BA, Blair JM, Mahan JD, Zibners L, Naumovski Z. A prospective comparison of bone density in adolescent girls receiving depot medroxyprogesterone acetate (Depo-Provera), levonorgestrel (Norplant), or oral contraceptives. J Pediatr 1996;129:671-6.

22. Kanis JA, Johansson H, Oden A, et al. A family history of fracture and fracture risk: a meta-analysis. Bone 2004;35:1029-37.

23. Cooper GS, Sandler DP. Long-term effects of reproductive-age menstrual cycle patterns on peri-and postmenopausal fracture risk. Am J Epidemiol 1997; 145:804-9.

24. Holick M. Vitamin D: importance in the prevention of cancers, type 1 diabetes, heart disease, and osteoporosis. Am J Clin Nutr 2004;79:362-71.

25. Lado F, Spiegel RR, Masur JH, Boro AA, Haunt SR. Value of routine screening for bone demineralization in an urban population of patients with epilepsy. Epilepsy Res 2008;78(2-3):155-60.

26. Dawson-Hughes B, Harris SS, Krall EA, Dallal GE. Effect of calcium and vitamin d supplementation on bone density in men and women 65 years of age and older. N Engl J Med 1997;337:670-6.

27. Draheim CC, Stanish HI, Williams DP, McCubbin JA, MacLean WE. Dietary intake of adults with mental retardation who reside in community settings. Am J Ment Retard 2007;112:392-400.

28. Farhat G, Yamout B, Mikati MA, et al. Effect of antiepileptic drugs on bone density in ambulatory patients. Neurology 2002;58:1348-53.

29. Lindsay R, Silverman SL, Cooper C, et al. Risk of new vertebral fracture in the year following a fracture. JAMA 2001;285:320-3.

30. Massachusetts Division of Health Care Finance and Policy. Health insurance coverage in Massachusetts: results from the 2008-2010 Massachusetts Health Insurance Surveys. December 2010. Available from: http://www.mass.gov/chia/docs/r/pubs/10/mhisreport-12-2010.pdf. Accessed November 9, 2013.
31. DeNavas-Walt C, Proctor BD, Smith JC. Income, poverty, and health insurance coverage in the United States: 2010. Current population reports. September 2010. Spauldings, MD: U.S. Census Bureau. Available from: http://www.census.gov/prod/2011pubs/ p60-239.pdf. Accessed November 9, 2013.

32. Wilkinson JE, Bowen D, Freund K, Rosen AK, Lauer E. Evaluating cancer screening outcomes in a Department of Mental Retardation Database. North American Primary Care Research Group, 36th Annual Meeting, Rio Grande, Puerto Rico, November 15-19, 2008, poster.

33. Global Campaign for Violence Prevention, Violence Prevention Alliance. The ecological framework. Geneva: World Health Organization. Available from: http://www.who.int/violenceprevention/approach/ ecology/en/index.html. Accessed November 9, 2013.

34. Elder JP, Lytle L, Sallis JF, et al. A description of the social-ecological framework used in the trial of activity for adolescent girls (TAAG). Health Educ Res 2006;22:155-65.

35. Agency for Healthcare Research and Quality. National Healthcare Quality Report 2011, AHRQ Publication No. 12-0005, March 2012. Available from: http://www. ahrq.gov/qual/qrdr11.htm. Accessed November 22, 2013.

36. Parish SL, Saville AW. Women with cognitive limitations living in the community: evidence of disability-based disparities in health care. Ment Retard 2006;44:249-59.

37. Wilkinson JE, Lauer E, Fruend KM, Rosen AK. Determinants of mammography screening in women with intellectual disability. J Am Board Fam Med 2011;24:693-703.

38. Alvarez N. Alzheimer disease in Down syndrome. Hoffmann M, editor. Updated March 2, 2012. New York: WebMD, Medscape Reference. Available from: http://emedicine.medscape.com/article/1136117overview. Accessed November 9, 2013.

39. Qaseem A, Snow V, Shekelle P, Hopkins R, Forciea MA, Owens DK. Screening for osteoporosis in men: a clinical practice guideline from the American College of Physicians. Ann Intern Med 2008;148:680-4. 